\title{
Transition to and Away from Injecting Drug Use among Young Drug Users in Tehran, Iran: A Qualitative Study
}

\author{
Afarin Rahimi-Movaghar, ${ }^{1}$ Alireza Noroozi ${ }^{1,2}$ Kimberly Page, ${ }^{3}$ Minoo Mohraz, ${ }^{4}$ William McFarland, ${ }^{3}$ \\ Hossein Malekafzali, ${ }^{5}$ and Mohsen Malekinejad ${ }^{6,}$ \\ ${ }^{1}$ Iranian National Center for Addiction Studies (INCAS), Tehran University of Medical Sciences (TUMS), Tehran, IR Iran \\ ${ }^{2}$ Department of Neuroscience and Addiction Studies, School of Advanced Technologies in Medicine (SATiM), Tehran University of Medical Sciences, Tehran, IR Iran \\ ${ }^{3}$ Department of Epidemiology and Biostatistics, Division of Preventive Medicine and Public Health and Global Health Sciences, University of California San Francisco, San \\ Francisco, USA \\ ${ }^{4}$ Iranian Research Center for HIV/AIDS (IRCHA), Iranian Institute for Reduction of High-Risk Behaviors, Tehran University of Medical Sciences, Tehran, IR Iran \\ ${ }^{5}$ Department of Epidemiology and Biostatistics, School of Public Health, Tehran University of Medical Sciences, Tehran, IR Iran \\ ${ }^{6}$ Institute for Health Policy Studies, University of California San Francisco, 3333 California Street, Suite 265, San Francisco, CA 94118, USA \\ "Corresponding author: Mohsen Malekinejad, Institute for Health Policy Studies, University of California San Francisco, 3333 California Street, Suite 265, San Francisco, CA 94118, \\ USA. Tel: +1-5108168555, Fax:+1-4154760705, E-mail: mmalekinejad@ucsf.edu
}

Received 2015 November 01; Revised 2016 July 31; Accepted 2016 December 25.

\begin{abstract}
Background: Iran has a large population of non-injection opioid users potentially at risk of initiation of drug injection.

Objective: We implemented a qualitative study to characterize the factors facilitating transition from non-injection drug use (NIDU) to injection drug use (IDU) and vice versa.

Materials and Methods: We conducted 42 in-depth interviews among purposefully selected groups of injecting and non-injecting drug users and health workers, in 2011 in Tehran, Iran. The interviews were audio-recorded, transcribed and coded using OpenCode 3.6 software.

Results: The predominant factor for transition from NIDU to IDU was a high level of drug dependence. IDU decreased the cost associated with drug use by several fold in the short-term. The influence of other injectors, either by learning directly from, encouraged by, feeling coerced by, or identifying with a lifestyle was also mentioned as a causal factor in the transition to IDU. Pleasure-seeking or desire to experience an immediate rush were rarely reported; rather, themes of the need to maintain functionality, reduce pain, and overcome financial difficulties emerged. Vein damage and other IDU-related physical health problems, as well as pressure from family were reasons for reverse transition (IDU to NIDU).

Conclusions: New harm reduction approaches could focus on blocking the transition from NIDU to injection and promoting the return to less harmful routes of administration.
\end{abstract}

Keywords: Iran, First Injection Episode, Initiation of Injection, Protective Factors for Injecting, Reverse Transition, Risk Factors for Injecting

\section{Background}

Through proximity to the world's largest source and a long history of use, Iran is one of the countries with the highest rate of opioid use in the world (1), with the primary pattern being smoking of opium. In the 2011 national household survey, 2.8 percent of the population aged 15 to 64 were estimated to meet the criteria for any substance use disorder $(2,3)$. It is also estimated that around 260,000 people use drugs via injection (4). In Iran, injecting drug use is the main route of HIV transmission and has contributed to approximately $70 \%$ of all HIV infections so far (5). People who inject drugs (PWID) are more than four times more likely to be infected with HIV than persons using drugs who do not inject (6). Hepatitis $B$ and $C$ virus infection are also reported to be high among PWID (7-10). The risk of infection with HIV and HCV is generally higher in the first years of injection $(11,12)$. Therefore, the window of opportunity to intervene after someone starts injecting drugs is short (12). Preventing initiation of injection and promoting the transition from injecting to non-injecting drug use can therefore be considered primary methods for preventing multiple infectious diseases and other health problems $(13,14)$.

Iran is the only country in the Middle East with largescale harm reduction programs, providing extensive opioid substitution treatment and needle and syringe distribution programs (15). Prevention interventions have targeted primarily PWID. However, there is a large population of non-injecting drug users who are at increased risk of initiating injection. Factors influencing initiation of injecting drug use have been studied in the developed world and in a few developing countries. However, information 
about factors facilitating the transition from non-injecting drug use (NIDU) to injecting drug use (IDU) and vice versa in the context of Iran (i.e., with exceptionally high opioid use) is scant (16).

This explorative qualitative study aimed to investigate individual, familial, environmental/social, and structural factors facilitating and preventing the transition to injection in young adult drug users. We aimed to explore perspectives and personal experiences of young drug users as well as their observations in their peers. We also interviewed healthcare workers regarding their perspectives and experiences.

\section{Materials and Methods}

\subsection{Study Design Overview}

This is a qualitative study in which we conducted faceto-face, in-depth interviews with a total of 42 young drug users and healthcare workers recruited from nine drug treatment centers in Tehran, Iran between July and October 2011.

\subsection{Study Participants and Sampling}

We recruited two types of participants: drug users and health workers. For drug users, we purposefully identified and selected four subgroups attending nine different drug use treatment and service facilities including: (1) noninjecting opium users $(\mathrm{n}=8),(2)$ non-injecting heroin or "kerack" (i.e., a highly concentrated and crystalized form of heroin) users ( $n=9)$, (3) injecting heroin or kerack heroin users ( $n=9)$, and (4) methamphetamine users $(n=9$, can be injector or non-injector). We included drug users who were: (1) 18 to 32 years old, (2) had a current or past history of opioid or methamphetamine use, and (3) had at least $\geq 6$ months of regular use of opioids or methamphetamine. We excluded drug users older than 32 years [the average age of drug users in Iran (17) in order to focus our study on factors more relevant to younger and early career use. We asked the staff of drug treatment centers to purposively identify information-rich clients with relatively strong and large social networks (social "hero") who were willing to share their knowledge and experience. We included at least two female and one Afghan (immigrant) participants for each group.

We recruited a total of seven health workers from the following categories: (1) substance use treatment specialists, (2) managers and outreach workers of harm reduction programs, (3) social workers and psychologists, and (4) researchers in the fields of drug treatment and harm reduction. We employed purposeful sampling to enroll diverse and information-rich key informants.

\subsection{Settings}

We conducted the study in Tehran, the capital city of Iran and with nearly 9 million inhabitants of diverse ethnic and socioeconomic backgrounds. Recruitment sites were drug use treatment or harm reduction centers selected from different tiers of drug services and located in geographically diverse areas of Tehran reflective of different socio-demographic characteristics of participants (Table 1).

\subsection{Data Collection Tool}

We developed an interview guide consisting of several sections including individual background information; current pattern of drug use; history of opiate use; history of stimulant use; history of injection practice; and the role of various factors on transition. The in-depth interview (IDI) guide included questions about participants' views on perceived factors influencing transition in the pattern and route of drug use. We pilot tested IDI guide among two drug users to examine the acceptability and comprehensibility of the guide and to inform the interview process. The results of the pilot interviews were used to modify and improve the guide and were excluded from analysis.

\subsection{Data Collection Procedures}

Interviewers were clinical psychologists with extensive experience. All study interviewers participated in a oneday implementation training session covering several topics including objectives of the study, how to screen potential participants based on the eligibility criteria, ethical considerations, interview procedures, non-judgmental and non-coercive interview skills, and the content of the IDI guide. The IDI training included role playing for the entire procedures under the supervision of an experienced qualitative researcher. A psychiatrist with an extensive experience in drug use research conducted interviews among the health workers at their work locations.

Interviewers screened drug users referred to our study by drug treatment facilities on eligibility criteria and obtained informed consent. Two interviewers jointly conducted and digitally audio recorded each interview, one who would ask questions and the other as note-taker. Interviews took place in a private room and on average lasted 92 minutes. We offered short breaks and refreshments during interviews. To compensate for time and travel cost, we remunerated 50,000 Iranian Rials (about US\$4) to participate. We also provided participants with a referral card for a free participation in group risk-reduction and psychoeducation sessions offered at the clinical research sites, as 
Table 1. Characteristics of Settings From Which the Interviewees were Recruited, Tehran, Iran, 2011

\begin{tabular}{|c|c|c|c|c|c|}
\hline Facility Type & Main Services & Location in Tehran & Financing & Gender of Clients & SES of Clients \\
\hline DTC \#1 & \multirow{4}{*}{$\begin{array}{l}\text { Outpatient, providing OST and structured } \\
\text { psychosocial services for stimulant treatment }\end{array}$} & West Tehran (Sadeghieh) & Private & Mainly male & Middle \\
\hline DTC \#2 & & North Tehran (Tajrish) & Private & Mainly male & Middle and High \\
\hline DTC \#3 & & South Tehran (Qazvin Sq) & Academic & Mainly male & Low and Middle \\
\hline DTC \#4 & & South Tehran (Shahr-e-Ray) & Private & Mainly male & Low and Middle \\
\hline DIC \#1 & \multirow{2}{*}{$\begin{array}{l}\text { Needle syringe program, low threshold MMT, } \\
\text { wound care and support services }\end{array}$} & South west Tehran (Azadi Sq) & NGO & Mainly male & Very low \\
\hline DIC \#2 & & South Tehran (Shoosh) & NGO & Exclusively female & Very low \\
\hline DIC \#3 & \multirow{3}{*}{$\begin{array}{l}\text { Short term (21 days) abstinence-based } \\
\text { psychosocial services for both opioids and } \\
\text { stimulants }\end{array}$} & South Tehran (Pamenar) & NGO & Mainly male & Very low \\
\hline RC \#1 & & West Tehran (Chitgar) & NGO & Exclusively male $(<25$ years $)$ & Low \\
\hline RC \#2 & & West Tehran (Chitgar) & NGO & Female & Low \\
\hline
\end{tabular}

Abbreviations: DIC, Drop-In Center; DTC, drug treatment center; MMT, methadone maintenance treatment; NGO, non-governmental organization; OST, opioid substitution treatment; RC, residential center; SES, socioeconomic status.

well as referrals to behavioral counseling and drug treatment clinics where they could receive comprehensive HIV prevention and drug treatment services if requested.

The study was reviewed for ethical considerations and approved by the committee on human research, University of California San Francisco (UCSF) and the ethics committee of Tehran University of Medical Sciences (TUMS).

\subsection{Data Analysis}

All interviews were precisely transcribed either by the same interviewers in charge of the interview or a research assistant note taker. One of the researchers conducted quality assurance on parts of each transcription to verify the accuracy.

For data analysis we used content analysis approach. We prepared a list of themes according to the study questions including: (1) the circumstances and factors related to initiating IDU; (2) protective factors preventing initiating IDU, and (3) the circumstances and factors related to switching back from IDU to NIDU.

We then identified preset categories for each theme through an interactive process and added new categories as they emerged through analysis. We further divided main categories into subcategories. We coded items while reading the transcribed text from the interviews. We used OpenCode 3.6 to analyze qualitative data.

Given that we observed negligible differences between responses of subgroups of participants (injecting vs. noninjecting, female vs. male, and drug users vs. health workers), we do not highlight differences and convergences in responses. Instead, we used participants' narratives to illustrate meanings in the themes and summaries and included the characteristics of the participants in parenthesis after each narration.

\section{Results}

From a total of 42 individuals participated in our survey; 35 were drug users and seven health workers. The 35 drug users were between the ages of 19 to 32 years (median 25) from whom nine were female, and sixteen had a history of IDU.

\subsection{The Pattern of Drug Injection and Initiation of Injection in the Participants}

The 16 drug users (two female and 14 male) with a history of drug injection were between the ages of 19 and 32 years, and educational levels ranging from 5 th grade to bachelor degree (median 10 years of education).

Most drug users considered kerack heroin (a highly concentrated and crystalized form of heroin) as their main injected substance, followed by heroin and morphine. Other substances reported for injection in the lifetime were: methamphetamine, norjisak (an injectable vial consisting of heroin, steroids, and other components), diazepam, and chlorpromazine.

Among those with a history of IDU, median age of initiation was 20 years (interquartile range 18,25 ). In the majority, kerack was the first injected substance. Heroin, temgesic (injectable buprenorphine), alcohol, and morphine were each reported by one drug user as the first injected drug. Only one started using drugs through an injection route. With respect to the frequency of injection after first experience, the majority reported daily injection, although some reported once per week or less.

\subsection{Individual Level Factors Influencing Injection}

Overall, participants more commonly reported individual level factors (vs. familial, social/environmental, and 
structural) for initiating injection with the following factors indicated more frequently in a descending order:

The intensity of addiction: Most participants stated that the intensity of addiction was the main reason for transitioning to injection and described it in two ways: 1) because of the need for an increased dosage of drug to control withdrawal, and inability to afford it, and 2) contrarily, disappearance of the high and pleasure, so they would turn to injection to reach that level of high. "I don't like to discuss chasing the pleasure. When I talk about pleasure, I feel we judge about someone who has got enough satisfaction in his life (General physician, age 35)." "If I show you my foot, you'll see that it's all black and I don't think (even) any insane person would do something like this to himself. My foot is destroyed...., but because of the intensity of my addiction, I've been always looking for a vein to inject and I've always called on the GOD, that: GOD! Give me a vein (IDU, male, age 29)."

Psychological problems: Participants very commonly considered emotional and psychological problems as important reasons for drug injection. Episodes of depression following a tragic event, lack of motivation, starting injection to commit suicide, and attracting attention or the pity of others were described as psychological issues or problems resulting in transition to injection. Failing in a romantic relationship was one such reason that triggered injection. "My brother wouldn't listen to me insisting that don't do this, don't do this (don't inject) ... later I got in trouble, I met a woman in a month and she left me, so I told my brother: come and do it for me, too (IDU, male, age 30)." "There is someone who was on Hashish before, then turned to injection. He was my boyfriend, because we got into a fight, he got to the injecting and he continued with injection (NIDU, female, age 20)."

One of the health workers indicated tragic events and associated mental factors following that event, as the most important reason for injection: "Injector, I feel is someone who has mental problems, for example is suicidal or selfmutilator, is seriously traumatized, have gotten into fights, has been imprisoned and relapsed a few times and is completely being messed up, who isn't in a mild addiction condition; ... I feel like in current situation, it's not a normal transition, I mean an unavoidable transition. For example, imagine that someone is using one gram of opium daily, it is almost normal if smoking 5 grams after a while, and then it becomes 6 grams ... This means that it's a normal progression, but shifting to injection is considered as a malignant jump. Usually there is an extreme major external factor, a huge stress, bankruptcy, reaching to an end (Psychiatrist, age 42)."

Curiosity: Some participants indicated curiosity as a reason for trying injection. The reasons for curiosity were seeking a way to use fewer drugs, while experiencing a stronger high, and experiencing the quick effect. Another person stated that he found it interesting seeing another person trying to find a vein in his hand and body.

Financial situation and living condition: A substantial number of participants mentioned a bad financial situation as the most important reason for addicts to shift to injection, with the cost of injecting temporarily lower than smoking or sniffing, due to the volume required. “... It was its cost as well; because our parents had limited us (me and my brother), they wouldn't give us money. They wouldn't give us more than 12 tomans [i.e., 12,000 Rials or 1 USD] daily, so we could get a gram each [of heroin], which the gram wouldn't work. It wouldn't cover our night through morning. We were forced to inject (IDU, male, age 30)."

A few people mentioned special life situations (e.g., homelessness) as a facilitating factor to injecting. However, one stated having a suitable physical space in his house as the factor influencing the shift. Another person mentioned a good financial situation as a protecting factor against injection.

Attitudes towards injecting drug use: Lack of awareness and being fearless about the consequences of injection and the assumption of being able to stop injecting upon decision were also mentioned as factors leading to injection. In fact, some perceived health benefits; one participant stated transitioning to injection as a way to keep the teeth healthy, he said: "My teeth are all healthy, because I've been using right [way]; but those who smoke all their teeth are carious, or they even don't have teeth. My own brother, his teeth have fallen; but if you inject, it won't damage teeth (IDU, male, age 30)."

Having a negative attitude toward injection was commonly considered a protective factor against drug injection. Most common negative attitudes reported by participants were: the fear of getting HIV or hepatitis and the possibility of transmitting them to spouses and family members, fear and negative feelings about syringes and their direct harm (e.g., blood, wounds, and skin infections), equating injection to severe addiction, death and deterioration of health, and the fear of revealing addiction and subsequent rejection by family and society. "Frankly, I didn't like it ... not sure how to say it, but I found it disgusting, blood and wounds on hands and things like that... I disliked these kinds of things, from my childhood (NIDU, male, age 23)." "Someone who injects drugs, soon will be recognizable by his face; that's why people avoid it; they don't want anyone knows when they're using. I knew that if someday I get there, everyone will realize and then I do not exist ... I always knew that drug injection is equal to death and I never envisioned that I want to go toward death by using drugs (IDU, female, age 30)." 
Some participants believed that transition to injection occurs less frequently in women than in men, because women are more likely to be afraid of injection, have negative attitude over drug injection (considering it as an obscene act), pay more attention to their physical appearance, and prefer to keep their drug use as a secret (that is, hiding the effects on the body).

Physical illness: Health conditions were rarely stated as the facilitating factor for injection drug use. A girl whose first experience of using drug was by injection said: "The first drug that I injected in my arm was temgesic ... I did it because of my pain [due to abortion], I wanted to have less pain. My brother-in-law injected it into my arm, and my pain was gone; so, I asked him to inject another syringe for me. (IDU, female, age 25)." "We had an accident with a motorcycle ... my brother was hospitalized for 48 hours; then they gave him some shots that you should inject it in your belly, and then throw it away... When he came out of the hospital, he would take the shots and use the same syringes to inject drugs (IDU, male, age 30)."

Special features of injection as a route of drug use: Many participants considered certain characteristics of injection (vs. other routes) as an important factor influencing the transitions from NIDU to IDU. The most important stated characteristic was the level of high and the fast effect. "The moment the drug would get injected into my body, my entire body would start itching as if hundreds of thousands ants were on my body. It was a strange feeling and I really liked the feeling and it would last for 7 - 8 minutes, and just for those 7 - 8 minutes I liked injecting (IDU, male, age 28)." "I've heard these same words from two people. They both said that injection affects faster, it goes to blood sooner, and gets into brain faster; but with smoke, it takes half an hour to an hour to reach the brain for us and to feel (NIDU, female, age 30)." "My brother would say: I can't get to finish my works, because smoking has a slow effect and I'm behind my work, it bothers me. That's why he started injecting (NIDU, female, age 30)."

The ease of use and quickness of injection was repeatedly mentioned as another feature. Also, one participant mentioned the lower risk of getting caught and arrested. "Injection is easier too. It takes 5 minutes to inject, while it takes an hour to smoke and then someone could come, or an officer could come. When you have syringe, you can just throw it away (NIDU, male, age 28)."

Also, one participant stated that injection would not let the drug being wasted. Some other participants thought that the type of substances could influence initiation of IDU and believed that by using kerack or heroin, transition to injection happened faster.

\subsection{Familial Factors Influencing Injection Drug Use}

Few participants considered familial aspects as influential factors on the route of drug use. Indeed, most participants believed that family had not played a role in their drug use route. "In fact in the beginning (of drug use), I learned the basics from my family, but for the rest, I searched and found friends like me who were users, and I learned more from them (NIDU, male, age 25)."

Family's reaction to drug use: Among participants who believed family plays a role in transitioning to injection, most felt it was in order to prevent their family finding out about their drug use. "You just throw the syringe out of the window and your family doesn't see it. This is important and they don't see. It neither has a smoke, nor anything ... (NIDU, female, age 30)."

One participant mentioned the family's harsh reactions to drug use, and their rejection as a cause for transition to injection. On the other hand, family reactions were also indicated as a preventive factor. Family pressure and control, fear of rejection, and family support were among preventive factors. "The family didn't play a role, they were inhibitors and would say not to inject; because they were afraid of death and disease; so they would tell me: smoke, but don't inject... when my father saw me injecting, he hit himself in head, he went for ablution and he prayed to God asking to take his life (IDU, male, age 29)." "See, if they (my family) wouldn't stop me, I would be an injector; I have to be honest. If my mother wouldn't bring me to the camp... they didn't let me to be an injector, with their love and control and not rejecting me, and staying with me (NIDU, female, age 24)."

Drug injection in the family: Some participants considered the presence of IDU in the family and being encouraged to inject by a family member as factors influencing their transition. Some participants reported having a brother, sister, or spouse who is PWID doing the first injection for them. For example, a 25-year old female indicated that her husband, sister, and brother-in-law were all injecting before she started and her brother-in-law did her first injection for her. "When my brother started injecting, I started as well. I wouldn't use this much, my length of use wouldn't match this much use (IDU, male, age 30)."

Dramatic life events in the family: Some participants mentioned dramatic life events (e.g., divorce, the death of father or brother, or imprisonment of brother) in the family as a factor for transition to injection. "When I started injecting, it was after my brother's death and I wanted to kill myself ... this caused me to start injection. In that time, I really wanted to be gone and I knew that injection is destruction (IDU, male, age 22).” 


\subsection{Social Network and Environmental Factors}

Learning from others (peer pressure): Many participants considered learning from friends and family as an important factor influencing transition from NIDU to IDU. Learning includes observation, encountering drug injection among other users, or hearing other users complimenting drug injection. Several participants reported the necessity of accompanying their IDU friends, injection being suggested by friends, and insistence on doing the first injection. The influential people were same- or oppositesex friends, prison mates, or fellow drug treatment camp internees. "My friend wanted to go to Turkey. We were very intimate friends. He was in a hurry and he didn't have time to smoke. He said that he wanted to inject; so, I injected because of him. That moment, I liked the "taste" of it very much (IDU, male, age 27)." "I had a friend and we had pocket-share. Lately we've been using drugs together. He wanted to inject and I wanted to smoke. From the financial point of view, the drug was not enough; he wanted to inject and I wanted to smoke, we couldn't get along. We wanted to remain friends in the same way; so I became injector (IDU, male, age 32)." "Frankly, there was a time that I was in withdrawal and I was feeling terrible, I didn't have much money to get it ... then one of my friends said, hey ... get this little (heroin) and inject it and be sure that the level of high is three times more than smoking it. Then he injected it in my arm (IDU, male, age 28)." "I went to the camp with my friend. In the camp, we learned stuff like shisheh [crystal] injection, and that it should be injected to the foot, then the body starts freezing from bottom up, or how you dissolve kerack, and drip it into these ear drops ... we learned these from the camp (IDU, male, age 30)."

Moving to or visiting places where drug injection is common (e.g., living in neighborhoods where drug use is prevalent), or where individuals can learn about different life styles and different behaviors (like military barracks, body building clubs, or group-living) were considered as other influential factors. "We changed our neighborhood, moved from Shahrak-e-Gharb to Hashemi; I met people who I should have never hung out with (Health Worker, exuser, age 34)." "My brother ... was doing body-building, he learned from the club, in the body-building clubs they inject all over their bodies for the sake of building it up (IDU, male, age 30)."

Some participants mentioned "not having an injection drug user among friends and family" or "their avoidance of drug injectors" as an important factor for not injecting. Some others mentioned that seeing the negative consequence of drug injection, such as overdose and death among their friends and family, as an inhibiting factor against injection drug use.
The availability, the cost and the quality of the drugs: Many participants mentioned limited availability of drugs, the necessity to pay less for drugs and the fall of the drug's quality as factors influencing transition to injection. "There was one of my friends who would grind kerack, and sniff it or smoke it. He would use two grams of kerack daily and it would cost him 20,000 tomans; but he would see me getting super rush with as low as 2,000 tomans, and he was amazed... he turned to injection and lowered his costs (IDU, male, age 28)."

The importance of these factors (availability, cost, and quality) on initiation of injection particularly in the prison environment was repeatedly highlighted.

Homelessness: Not having a place to smoke was mentioned as a factor influencing the initiation of injection in the context of homelessness.

\subsection{Structural and Societal Conditions}

Two factors were mentioned as structural and social level facilitators for drug injection. First, the fast living pace in today's society that can draw the youth towards injection. "These incidents first of all occur more frequently amongst the new generation. It has a meaningful association with younger age ... the knot between the speed, in the new living ... in different aspects of life. As the same way that the person wants to get to his work faster, as he prefers a Mc Donald over cooking Ghormeh Sabzi (an Iranian food), for the same reason he chooses to use heroin, and inject it. The logic is the same, the logic of speed (General Physician, age 45)."

Second, there is a lack of differentiation between various substances and routes of drug use (with different level of harm) in media campaigns. This leads to a uniform attitude towards any kind of substance and methods of use in the society. "Radio and Television, our newspapers, magazines and the satellite channels, they are all ineffective or put very little effort; for example, the message that all kinds of substance use are bad, and they're all equally bad. When this is said, then folks wouldn't see the difference between opium and heroin, and smoking or injection. They feel already being in the game, meaning they don't distinguish between the more risky and less risky patterns. This culture of the more risky or less risky pattern has not found its way into our information dissemination and media (General Physician, age 45)."

On the other hand, a few participants reported that the change in the social norms and media campaigning (especially by radio and television) against drug injection was important inhibiting factor for drug injection. Moreover, the "traditional desire for opium (the drug that injection use is less likely)" was considered as a protective factor for drug injection. 
3.6. Factors Influencing the Transitions from Injection to NonInjection (Reverse Transition)

The majority of participants said they had never encountered an injection drug user who has been able to switch to non-injection and they believed that this pattern cannot happen due to following reasons: the effect and intensity of euphoria induced with drug injection, perceived lower cost, the severity of addiction with drug injection, and occurrence of intense withdrawal symptoms when transiting to non-injection. “I've never seen it; I don't think it can happen. Many of those who inject don't want to go a level down. They either want to completely stop using, or continue with their use ... a friend who was injecting kerack, I asked him what would happen if you smoke the kerack now? He told me: I can never get high and I have to inject in order to be able to stand on my feet(NIDU, male, age 25$). "$

The participants who had seen the transition from injection to non-injection considered "inability to find veins for injecting" as a principal reason for the reverse transition. Others considered factors such as: "the incidence of physical problems" (e.g., contracting skin infections, AIDS, hepatitis $\mathrm{C}$, and decrease in sexual drive and functionality), "paying attention to health and appearance", and "the fear of contracting infectious diseases" as drivers of reverse transition. "Yes, this is very common; I mean I've seen it a lot; for instance he says I've been in injection for 2 - 3 months, but I saved myself again and quit injecting and I realized that it was damaging me, it was destroying my veins, I was in a very bad shape; so I quickly switched back to sniffing; either kerack, or Shishah (crystal). I feel that unlike kerack to opium which its reverse gear is more difficult, shifting from injection to non- injection is more possible now; I see a lot who can come out of it, with a friend's help, some extra money and a few veins that hurt, help them to go back (Psychiatrist, age 42)." "He sees that the needle goes into his skin and he can't find a vein, he sees that he can't get a response from it and he's in pain. Then he sees that it takes 15 minutes to get the drug into his body and he is suffering and his blood keeps clotting and he is in withdrawal and he says to himself, where he's going to get drugs from, and he has to beg others to inject for him for God sake. That's when he is fed up and starts smoking (IDU, male, age 28)." "Ever since I did an HIV test and found out I'm sick, I hated it. Even though my love was injection; ... I injected for 2-3 months, then I quit and then started injecting again and maybe overall it's not even a year (IDU, male, age 25)." Some participants believed that older drug users have a higher chance for quitting injection due to better understanding of associated damages in addition to overall physical weakness and damaged veins.
Some participants believed that some PWID after a period of drug abstinence and after relapse may continue using drug without injection. "I saw someone who was injecting and they took him to the camp. Morphine cleared out of his body and then he come out and became smoker (NIDU, male, age 21)."

Familial factors (e.g., fear of being rejected by family, the necessity of having the family's support) were indicated as important reason for shifting back from IDU to NIDU. "Yes, I switched my injection to smoking 2 - 3 times. The situation in my family affected it; like when a family keeps saying that he's an injector and pokes syringes in his body. Well, then he starts smoking. When there's a wound in his body or his sleeve is bloody, and he doesn't want his mom to notice; that's why he continues with smoking kerack(IDU, male, age 28)." "After the tension goes away, for example after a week that they wouldn't let him in the house and he had to sleep on the streets because of his injection, and then when they let him in and he finds a roof over his head, he quits injecting; means that after the stress and tension is gone, he will go back (Psychiatrist, age 42)." "I, for instance, can sit next to my family and drink alcohol and smoke opium freely and easily; because they wouldn't bother; but for example, I can't inject in front of my parents or around my family, so that's why if I want to stay at home and enjoy it with my family, it's better if I smoke(IDU, male, age 28)."

Other factors indicated by participants were including: "the fear of getting arrested while buying syringes", "the fear of deterioration", due to the severity of addiction and losing everything such as health, family, and social reputation and death in the ruins.

\section{Discussion}

The present study is an in-depth investigation and first of its kind conducted in Iran focusing on the reasons underlying transition to or from injecting drug use among young adults in Iran. We explored multiple interrelated protective and risk factors at individual, family, community, and structural levels.

"Increased drug dependence" and "feeling the effect of drug with lower dose of drug, by injection" were commonly indicated individual level factors influencing the transition to IDU. Long duration of drug use $(18,19)$, more frequent drug use (14), higher amount of daily drug use (20) are indicators of a greater involvement with drug dependence. Increased drug dependency usually results in increasing the cost of the daily drug use and thus a motivation for shifting to injection. A considerable number of participants described that how injection helps in decreasing the cost of drug use several fold and in short-term. 
Other studies have also suggested that the high cost of drug use can contribute to transition to IDU (11, 21-23), since injecting is the most efficient route. The need to reduce drug expenses is more pronounced in those with scarce economic resources (e.g., homeless and unemployed people) $(14,18,24)$.

Another individual level factor that was discussed by the majority of participants was "facing a loss or psychological problem". Other studies reported stress and experience of loss as a precipitating factor, as well $(14,18)$. The loss or severe stress can lead to depression or decreased self-esteem, problems that drug users may seek a relief through injection drug use.

Although the "desire to experience the immediate rush" has been indicated as a factor for intravenous use of drug in other studies (25-27), participants in our study rarely mentioned such an effect. Some of the participants even rejected such motivation for NIDU to IDU transition, and instead indicated the need to maintain their function, reduce pain and suffering, and overcoming financial difficulties that are far from the concept of "pleasure-seeking behavior".

The majority of participants described the influence of others as an important factor in the initiation of drug injection mediated through learning from, encouraged by, or coerced by others. The others included friends, family members or relatives, and inmate peers. Further, "lifestyle similarities" between a non-injector and an injector had resulted in the transition. Exposure to other IDUs as a factor influencing the transition to drug injection has been widely documented in other studies, as well $(14,18,24$, 28 30).

We also identified two domains of preventive factors against the initiation of injection. The first one was negative attitudes towards the injection. One stemmed from fear of HIV infection and hepatitis, needles and blood, and more severe drug dependency and death. Fear of death (observing other injectors die) was also reported as the main reason for switching from IDU to NIDU by another study in Iran (31). The second domain of preventive factors stemmed from family-related issues including being controlled by family and fear of being rejected by family.

Most participants rejected the possibility of the permanent reverse transition, that is, switching back from IDU to NIDU permanently. The commonality of such a transition is not well-known. A study showed that a small proportion (1\%) of drug users in Iran switched from IDU back to NIDU (32). However, in another prospective study conducted in Iran, the switching from IDU to NIDU was reported to be more prevalent than the other way around (31). At least three studies from United States (New York), the Netherlands (Amsterdam), and India (Chennai) have corroborated the possibility of reverse transition, as well (13, 33-35).

Participants mainly associated reverse transition with the development of vein damage and other health problems as a reason. Only a few reported the fear from HIV infection and other health problems or general health and social deterioration, as preventive and reverse transition factor, suggesting that many switch back after a problem rises. In the contrary, concerns about becoming infected with HIV as a reason for reverse transition had been reported frequently in studies from other countries $(13,18,33$, 34).

The risk of HIV, hepatitis B and C infections is the highest in the first years of initiating IDU $(11,12,21)$. Most HIV prevention efforts reach to PWID only several years after initiation (21). Therefore, it is crucial to identify and access drug users at risk for injection and prevent them from early transitioning. As our study has shown that noninjecting drug users often initiate injection under influence of their peer injectors, innovative interventions based on social networks, [e.g. (36)] can be used to target young NIDU at risk of transitioning to IDU. Given that HIV infection in Iran is mainly attributed to injecting drug use, there is an opportunity to educate injecting and non-injecting drug users about it. Increasing awareness among family of drug users, especially if they are already supportive of non-injection drug use may also promote reverse transition (13). Factors serving as points of intervention include highlighting negative attitudes against injection (21), encouraging NIDU to correctly assess the consequences of injecting (19), and encouraging injectors not to promote injection among NIDU $(18,37)$. Accessibility of various drug treatment facilities is also crucial in preventing transition or promoting reverse transition $(16,19)$.

Our study has several limitations. Due to the nature of qualitative research, findings from this study should not be generalized to all drug users in Iran, and causality should be interpreted cautiously. Further, it is possible that we were not able to capture many other important factors in the experiences of our study participants. In addition, participants could have misremembered stories or avoided to elaborate all aspects of their own or their friends' histories. However, the interviewers were experienced and specifically trained for providing a nonjudgmental and supportive environment in which the participants desire to open-up their stories.

We recommend that themes and factors identified from this study being quantitatively tested in a large epidemiologic studies (ideally longitudinal cohort studies) in order to establish evidence of causal association between these factors and critical transitional stages. Lessons learned about potential preventive factors can be used to 
develop intervention strategies and being tested in the field.

\section{Conclusion}

This study revealed that predominant factor for transition from non-injecting to injecting drug use was a high level of drug dependence and social network plays key role in persuading initiation of injection. Pleasure-seeking or desire to experience an immediate rush were rarely reported. Physical health problems, as well as pressure from family were reasons for reverse transition. New harm reduction approaches are needed to block the transition from NIDU to injection and promoting the return to less harmful routes of administration.

\section{Acknowledgments}

The authors would like to thank Dr. Maryam Foroughi and managers of the Rebirth Society Organization and managers of centers of Ayandeh, Azadi, Etemad, Iranian National Center for Addiction Studies, Khane-Khorshid, Mehr-ayeen, and Pamenar. We would also like to extend our gratitude to the interviewers, as well as all the participants in the study.

\section{Footnotes}

Authors' Contribution: Mohsen Malekinejad, Kimberly Page and William McFarland conceived the study. All authors participated in designing the study. Afarin Rahimi-Movaghar, Alireza Noroozi, Mohsen Malekinejad performed the analysis and interpreted the data. Afarin Rahimi-Movaghar, Alireza Noroozi, Mohsen Malekinejad drafted the manuscript. All authors read, commented and approve the final manuscript.

Funding/Support: This study was supported by a grant from the US national institute for drug abuse (NIDA) (Grant No. 1R21DA029473-01).

\section{Declaration of Interest: None declared.}

\section{References}

1. United Nations Office on Drugs and Crime . World Drug Report. Vienna: UNODC; 2011.

2. Sharifi V, Amin-Esmaeili M, Hajebi A, Motevalian A, Radgoodarzi R, Hefazi M, et al. Twelve-month prevalence and correlates of psychiatric disorders in Iran: the Iranian Mental Health Survey, 2011. Arch Iran Med. 2015;18(2):76-84. [PubMed: 25644794].

3. Amin-Esmaeili M, Rahimi-Movaghar A, Sharifi V, Hajebi A, Radgoodarzi R, Mojtabai R, et al. Epidemiology of illicit drug use disorders in Iran: prevalence, correlates, comorbidity and service utilization results from the Iranian Mental Health Survey. Addiction. 2016;111(10):1836-47. doi: 10.1111/add.13453. [PubMed: 27177849].
4. Rahimi-Movaghar A, Amin-Esmaeili M, Haghdoost AA, Sadeghirad B, Mohraz M. HIV prevalence amongst injecting drug users in Iran: a systematic review of studies conducted during the decade 1998-2007. Int J Drug Policy. 2012;23(4):271-8. doi: 10.1016/j.drugpo.2011.09.002. [PubMed: 22000694].

5. Iran Ministry of Health . Iran, Progress Report on Monitoring of the United Nations General Assembly Special Session on HIV/AIDS. [in Persian].;2012.

6. Amin-Esmaeili M, Rahimi-Movaghar A, Haghdoost AA, Mohraz M. Evidence of HIV epidemics among non-injecting drug users in Iran: a systematic review. Addiction. 2012;107(11):1929-38. doi: 10.1111/j.13600443.2012.03926.x. [PubMed: 22551085].

7. Amin-Esmaeili M, Rahimi-Movaghar A, Razaghi EM, Baghestani AR, Jafari S. Factors Correlated With Hepatitis C and B Virus Infections Among Injecting Drug Users in Tehran, IR Iran. Hepat Mon. 2012;12(1):23-31. doi: 10.5812/kowsar.1735143X.806. [PubMed: 22451840].

8. SeyedAlinaghi SA, Kheirandish P, Karami N, Salem S, Shirzad H, Jahani MR, et al. High prevalence of chronic hepatitis B infection among injection drug users in Iran: the need to increase vaccination of adults at risk. Acta Med Iran. 2010;48(1):58-60. [PubMed: 21137671].

9. Tavakkoli H, Mir-Nasseri MM, Poustchi H, Afshar P, Motalebi MN, Mohammadkhani A, et al. Prevalence and risk factors of hepatitis $B$ infection in injection drug users, Tehran (2001-2002). Hepat Mon. 2008;8(1):29-33.

10. Zobeiri M, Adibi P, Alavian SM. Intravenous drug use and hepatitis C virus in iran. Hepat Mon. 2012;12(1):9-10. doi: 10.5812/kowsar.1735143X.797. [PubMed: 22451838].

11. Young AM, Havens JR. Transition from first illicit drug use to first injection drug use among rural Appalachian drug users: a cross-sectional comparison and retrospective survival analysis. Addiction. 2012;107(3):587-96. doi: 10.1111/j.1360-0443.2011.03635.x. [PubMed: 21883604].

12. Miller CL, Pearce ME, Moniruzzaman A, Thomas V, Christian W, Schechter MT, et al. The Cedar Project: risk factors for transition to injection drug use among young, urban Aboriginal people. CMAJ. 2011;183(10):1147-54. doi: 10.1503/cmaj.101257. [PubMed: 21670106].

13. Des Jarlais DC, Arasteh K, Perlis T, Hagan H, Heckathorn DD, McKnight $\mathrm{C}$, et al. The transition from injection to non-injection drug use: longterm outcomes among heroin and cocaine users in New York City. Addiction. 2007;102(5):778-85. doi: 10.1111/j.1360-0443.2007.01764.x. [PubMed: 17506155].

14. Sanchez J, Chitwood DD, Koo DJ. Risk factors associated with the transition from heroin sniffing to heroin injection: a street addict role perspective. J Urban Health. 2006;83(5):896-910. doi: 10.1007/s11524006-9059-0. [PubMed:16937089].

15. Rahimi-Movaghar A, Amin-Esmaeili M, Aaraj E, Hermez J. Assessment of situation and response to drug use and its harms in the Middle East and North Africa, 2012. Middle East and North Africa Harm Rediction Association; 2013.

16. Malekinejad M, Vazirian M. Transition to injection amongst opioid users in Iran: implications for harm reduction. Int J Drug Policy. 2012;23(4):333-7. doi: 10.1016/j.drugpo.2011.09.001. [PubMed: 21996166].

17. Narenjiha H, Rafiei $H$, Baghestani AR, Nouri R, Ghafouri B, Soleimaninia L. Rapid situation assessment of drug abuse in Iran. Tehran: Danjeh publication; 2007.

18. Neaigus A, Miller M, Friedman SR, Hagen DL, Sifaneck SI, Ildefonso $G$, et al. Potential risk factors for the transition to injecting among non-injecting heroin users: a comparison of former injectors and never injectors. Addiction. 2001;96(6):847-60. doi: 10.1080/09652140020050960. [PubMed: 11399216].

19. Roy E, Nonn E, Haley N. Transition to injection drug use among street youth-a qualitative analysis. Drug Alcohol Depend. 2008;94(1-3):19-29. doi: 10.1016/j.drugalcdep.2007.09.021. [PubMed: 18077104]. 
20. Neaigus A, Gyarmathy VA, Miller M, Frajzyngier VM, Friedman SR, Des Jarlais DC. Transitions to injecting drug use among noninjecting heroin users: social network influence and individual susceptibility. J Acquir Immune Defic Syndr. 2006;41(4):493-503. doi: 10.1097/01.qai.0000186391.49205.3b. [PubMed:16652059].

21. Vlahov D, Fuller CM, Ompad DC, Galea S, Des Jarlais DC. Updating the infection risk reduction hierarchy: preventing transition into injection. J Urban Health. 2004;81(1):14-9. doi: 10.1093/jurban/jth083. [PubMed: 15047779].

22. Razani N, Mohraz M, Kheirandish P, Malekinejad M, Malekafzali $\mathrm{H}$, Mokri A, et al. HIV risk behavior among injection drug users in Tehran, Iran. Addiction. 2007;102(9):1472-82. doi: 10.1111/j.13600443.2007.01914.x. [PubMed: 17645427].

23. Bravo MJ, Barrio G, de la Fuente L, Royuela L, Domingo L, Silva T. Reasons for selecting an initial route of heroin administration and for subsequent transitions during a severe HIV epidemic. Addiction. 2003;98(6):749-60. [PubMed: 12780363].

24. Roy E, Haley N, Leclerc P, Cedras L, Blais L, Boivin JF. Drug injection among street youths in Montreal: predictors of initiation. J Urban Health. 2003;80(1):92-105. doi: 10.1093/jurban/jtg092. [PubMed: 12612099].

25. Darke S, Cohen J, Ross J, Hando J, Hall W. Transitions between routes of administration of regular amphetamine users. Addiction. 1994;89(9):1077-83. [PubMed: 7987184].

26. Draus PJ, Carlson RG. Needles in the haystacks: the social context of initiation to heroin injection in rural Ohio. Subst Use Misuse. 2006;41(8):1111-24. doi: 10.1080/10826080500411577. [PubMed: 16798679].

27. Dunn M, Degenhardt L, Bruno R. Transition to and from injecting drug use among regular ecstasy users. Addict Behav. 2010;35(10):90912. doi: 10.1016/j.addbeh.2010.06.007. [PubMed: 20587367].

28. Abelson J, Treloar C, Crawford J, Kippax S, van Beek I, Howard J. Some characteristics of early-onset injection drug users prior to and at the time of their first injection. Addiction. 2006;101(4):548-55. doi: 10.1111/j.1360-0443.2006.01379.x. [PubMed: 16548934].
29. Koram N, Liu H, Li J, Li J, Luo J, Nield J. Role of social network dimensions in the transition to injection drug use: actions speak louder than words. AIDS Behav. 2011;15(7):1579-88. doi: 10.1007/s10461-0119930-1. [PubMed: 21431412].

30. Khobzi N, Strike C, Cavalieri W, Bright R, Myers T, Calzavara L, et al. A qualitative study on the initiation into injection drug use: Necessary and background processes. Addict Res Theory. 2009;17(5):546-59. doi $10.1080 / 16066350802011664$.

31. Jafari S, Rahimi-Movaghar A, Craib KJP, Baharlou S, Mathias R. A follow-up study of drug users in Southern Iran. Addict Res Theory. 2009;18(1):59-70. doi: 10.3109/16066350902825930.

32. De Kort G, Batra S, Pasaribu R, Vazirian M, Ul-Hassan S. Young people and drugs - Towards a comprehensive health promotion policy, final report. Thailand: Asian Harm Reduction Network (AHRN); 2005.

33. de la Fuente L, Barrio G, Royuela L, Bravo MJ. The transition from injecting to smoking heroin in three Spanish cities. The Spanish Group for the Study of the Route of Heroin Administration. Addiction. 1997;92(12):1749-63. [PubMed: 9581007].

34. Mehta SH, Sudarshi D, Srikrishnan AK, Celentano DD, Vasudevan CK, Anand S, et al. Factors associated with injection cessation, relapse and initiation in a community-based cohort of injection drug users in Chennai, India. Addict Res Theory. 2012;107:349-58.

35. van Ameijden EJ, Coutinho RA. Large decline in injecting drug use in Amsterdam, 1986-1998: explanatory mechanisms and determinants of injecting transitions. JEpidemiol Community Health. 2001;55(5):35663. [PubMed: 11297661].

36. Fuller CM, Vlahov D, Ompad DC, Shah N, Arria A, Strathdee SA. Highrisk behaviors associated with transition from illicit non-injection to injection drug use among adolescent and young adult drug users: a case-control study. Drug Alcohol Depend. 2002;66(2):189-98. [PubMed: 11906806].

37. Hunt N, Griffiths P, outhwell M, Stillwell J, Strang J. Preventing and curtailing injecting drug use: A review of opportunities for developing and delivering'route transition interventions'. Drug Alcohol Rev. 1999;18(4):441-51. 